\title{
SELF- AND PEER-ASSESSMENT TO ENHANCE STUDENT ENGAGEMENT IN UNDERGRADUATE GROUP PROJECTS
}

\author{
Dermot Kerr, \& Sonya Coleman \\ School of Computing, Engineering and Intelligent Systems, Ulster University (UK)
}

\begin{abstract}
Group projects are an important part of undergraduate computer science learning because of their role in developing working skills which are vital for professionals in the computing industry. While group projects offer many potential learning benefits there is no guarantee that the development of working skills will be achieved. In fact, group projects introduce their own stresses and strains for students due to the need to share the workload as fairly as possible, in how individual contributions are measured and recognised, the effect this has on individual performance, and ultimately how this contributes to the student's success in the course. Group projects which are not designed, supervised and assessed in a way that promotes meaningful teamwork and collaboration can lead to failure. In this paper we demonstrate practical use of the WebPA system to allow students to perform self- and peer-assessment to effectively measure individual contributions within group projects. The impact of the tools in supporting and measuring performance is validated through quantitative student feedback where we demonstrate significant student engagement in the assessment process and student satisfaction in mark allocation.
\end{abstract}

Keywords: Peer-assessment, self-assessment, group projects, computer science, WebPA.

\section{Introduction}

The concept of peer-assessment (also known as peer review) has been used in education and beyond for many years. It provides a transparent mechanism through which students can critique and provide summative feedback to their fellow students on their work. Additionally, this may encourage students to take an independent approach to their own personal learning. For example, self and peer assessment encourages students to engage with the assessment criteria and also to reflect on their own performance as well as the performance of their fellow students. This is considered by many as an important process as developing and providing peer feedback to other students also assists students in developing critical thinking skills and objective evaluative judgements based on the assignment criteria. Additionally, beyond that it provides students with an opportunity to develop lifelong and transferable skills in assessing and providing feedback to others, in home life, education and the workplace. Moreover, it equips students with the skills and self-awareness to self-assess and improve their own work.

Peer assessment comes with its own challenges, both in terms of giving and receiving peer feedback. Some people will naturally be severe in their assessments and some students will respond badly to that, sometimes causing them to question the value of their work. Additionally, people can be wrong when it comes to the assessment of another's work. Therefore, this should be overseen by a lecturer or person responsible for the course delivery. However, one of the advantages of peer assessment is that it provides students with deep learning and a deeper understanding of the assessment process. In order to allow students to properly assess the work of their peers, they need to acquire a thorough understanding of the assessment criteria and the assignment itself; this naturally promotes a deeper learning (Hughes, 1995). As a consequence, this deep learning and self-evaluation can have a significant impact on their subsequent performance (Brown 1994; Falchikov 2007). Peer assessment also has clear benefits for teaching staff. It has the potential to reduce the workload of assessment marking by placing some responsibility on students and help to alleviate the pressures associated with large classes and other difficulties. However, this is only achieved if significant effort is attributed to designing the peer assessment at the beginning; in order to make it work successfully, the students must understand what it is, why its being carried out and how it will work. This paper analyses student feedback on the use of Web-PA to attribute weighted marks to individual group members for a group assessment in a UX course. In general, the students considered the use of Web-PA as fair and equitable. 


\section{Methodology}

The study is based on a group project for undergraduate students studying Computer Science, Software Engineering and Information Technology. All students were enrolled on a 12-week second year module on the topic of UX and user interface design. Students were divided into groups of four through a process of student self-assigned groups, with any remaining students assigned to groups by the lecturer. In the study presented here there were 120 students in the cohort resulting in 30 student groups. The groups were tasked to develop a user interface to solve a real-world problem using one of ten provided scenarios. Each scenario asked the students to develop a web-based user interface for a desktop or mobile device. The overall aim of the group project was to develop core competency and confidence in client-side web development while appreciating the need for user-centred design (Monk, 2000). Essentially, this requires the students to understand the intended users, their needs, and the context of their actions - only then is the actual system design considered in terms of what it should look like, and how the design should be based on real people, with real tasks and needs. User-centred design is a hands-on process that requires student groups to identify actual users (stakeholders), conduct a focussed discussion on the tasks they are trying to complete, and thoroughly understand the context and environmental constraints of their work. Students will then base their initial design solutions on the outcome of such discussions although the first designs are likely to be rough drafts and problematic. Students are expected to work in groups to identify potential user-related issues by using a strategy that enables continuous evaluation of the proposed design. It is essential for students to work as a group to appreciate both user and business needs and apply and reflect on user-centred design techniques as part of their learning experience. Group work facilitates the development of transferable skills that are essential in employment, such as compromise, cooperation, negotiation, delegation, etc. Students also learn from each other. Students have different ideas and contributions on the requirements, design and implementation stages; this combined input is essential to appreciate user-centred design. Once students have completed their projects they are subsequently tasked to self- and peer-review the other members of their group using 5-point criteria that was defined by the students during the semester.

\subsection{Web based peer review}

Assigning a single mark to a group project is often a worry for undergraduate students. A common perception is that individuals working on the project are not given the credit they deserve for their contributions, and group members who don't put in effort receive the same marks as those who have contributed strongly. Peer assessment permits better grading of a student's abilities against a range of important transferable skills that they will have to demonstrate as graduates, such as communication, leadership, presentation skills, working as part of a team, etc. Completing the peer-assessment is a key aspect of learning as it ensures students reflect and assess their group peers' abilities as well as their own abilities.

The selected peer assessment system, Web-PA, was developed in Loughborough University as a web-based system for both self and peer assessment (Willmot and Crawford, 2004). It has been used across a number of faculties at Loughborough for several years. Web-PA can handle large classes of students and has been previously described in detail by the authors (Willmot and Crawford, 2004). It provides an easy way by which individuals can be assigned a proportion of the overall project mark based on information provided by individual members of the groups. Web-PA allows the teaching staff to establish a number of criteria against which each group member marks themselves (self) and each of the other group members (peers). This is typically completed at the end of a project but could also be carried out at prescribed times throughout the project lifetime. Students can enter data in confidence and the system calculates a variation factor (called the Web-PA factor) for each individual member of the group based on the normalised total score. The teaching staff marks the group project submission in the normal manner and this mark, or part of it, is weighted by the calculated variation factor for each individual. In the case when all group members score equally, the Web-PA factor $=1.0$, therefore all members achieve the unmodified team mark. There is some early evidence of higher levels of student satisfaction with respect to group work since Web-PA was introduced (Gatfield, 1999).

\section{Evaluation}

A questionnaire was designed for the students with a purpose of gathering quantitative feedback on the use of the Web-PA system for self- and peer- assessment. In general, the students considered Web-PA a fair means of calculating weighted factors for individual contributions. In total 37 students completed the questionnaire, and the key results are presented in Figure 1. In Figure 1(a) we can see that $>75 \%$ students agreed or strongly agree that Web-PA was a good approach to peer assessment. Figure 
1(b) illustrates that approximately $72 \%$ found the assessment to be fair and reasonable and we believe this satisfaction rate can be attributed to the use of Web-PA. It should also be noted that satisfaction can be anecdotally measured by general student satisfaction of the module during the staff-student consultative process; many less queries and issues with the group assessment were raised.

Figure 1. Quantitative evaluation of survey responses to two categories: (a) "I found the assessment fair and reasonable"; (b) "I found the Web-PA assessment a good way to evaluate my own and others' contribution to the project".

(a)

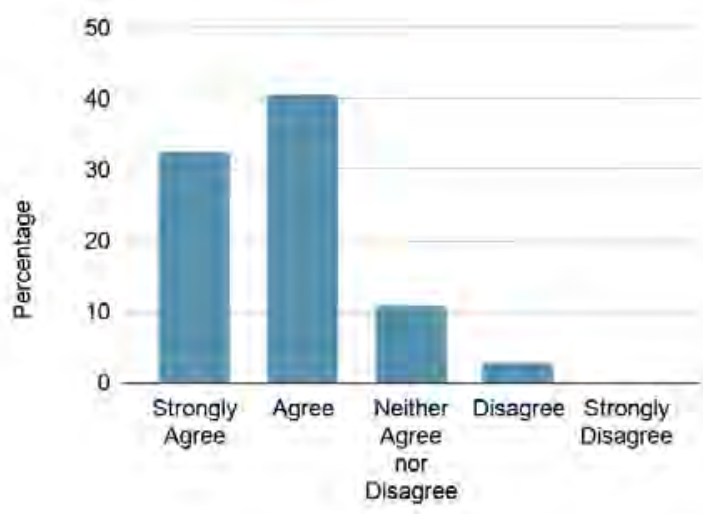

(b)

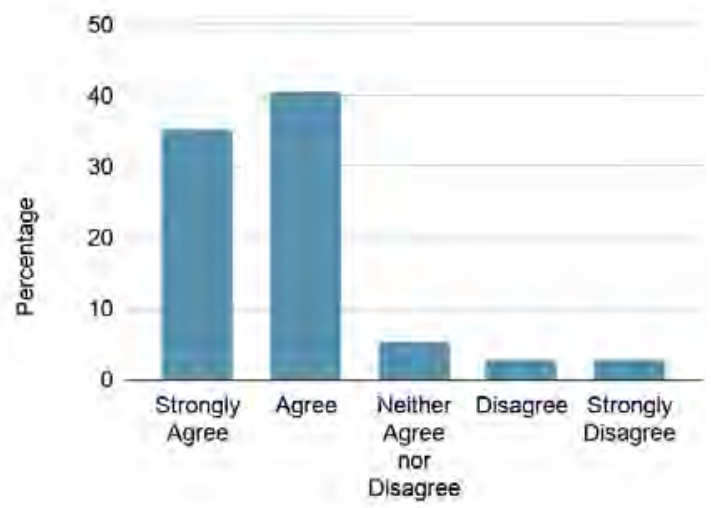

\section{Conclusion}

When students contribute to their marking criteria research has shown that student learning is enhanced. The criteria used must be clear and transparent for your students in order for them to assess the work of their peers. This process of peer and self-assessment supports the students in learning to understand what is meant by high quality and they can also learn from their peers that there may be different approaches to successfully completing an assignment. This peer assessment was conducted with second year students, such skills will be transferable to their placement and final years and will ideally lead to increased course engagement. Peer assessment can provide frequent and relevant formative feedback that students can act upon in a valuable way.

Peer assessment is an excellent way to encourage students to actively participate in group activities. As the students get the opportunity to mark each other and therefore be evaluated by others which prevents them from 'hiding' in a group. This increased engagement naturally improves the learning and teaching experience for the students, ensuring that they fulfil all module outcomes. The student feedback on this approach was very positive and the modules marks, and attendance illustrated an improvement over previous years. Therefore, this will be used in the UX module in the forthcoming year.

\section{References}

Brown, S. Rust, C. \& Gibbs, G. (1994). Strategies for Diversifying Assessment in Higher Education. The Oxford Centre for Staff Development, Oxford. Oxonion Rewley Press.

Falchikov, N. (2007). In: Rethinking Assessment in Higher Education (Boud, D. \& Falchikov, N., eds.), pp. 128-144. Abingdon. Routledge.

Gatfield, T. (1999) Examining student satisfaction with group projects and peer assessment. Assessment and Evaluation in Higher Education, 24 (4), 365-377.

Hughes, I E (1995) Peer assessment of student practical reports and its influence on learning and skill acquisition. Capability, 1, 39-43

Monk, A., (2000), June. User-centred design. In International Conference on Home-Oriented Informatics and Telematics (pp. 181-190). Springer, Boston, MA.

Willmot, P., Crawford, A., R. (2004) Online peer assessed marking of team projects. Proceedings of the International Conference on Engineering Education, ICEE 2004, Paper WA7/4, Gainesville, Florida, USA, October 2004, 1-7. 